\title{
EL HÉROE ARTISTA EN LA NOVELA CORTA DE FIN DE SIGLO
}

\author{
Diego Mejía Estévez \\ Universidad Nacional Autónoma de México \\ diego.mejia.estevez@gmail.com
}

Resumen: Este artículo discurre sobre uno de los géneros más representativos del siglo XIX, el Künstlerroman (el cual se desarrolla a la par del auge definitivo de la novelística), y las principales formas narrativas, a menudo diferenciadas con base en su mayor o menor extensión. No obstante su origen en la tradición alemana, la también llamada novela de artista se difunde en las literaturas europeas de mayor relieve y arriba del mismo modo al ámbito hispánico, especialmente rico y complejo durante el fin de siglo. Una comparación entre una novela realista de gran extensión (El doctor Centeno de Benito Pérez Galdós), una novelita posromántica (Confesiones de un pianista de Justo Sierra) y un cuento plenamente modernista ("El pájaro azul" de Rubén Darío), propone un resumen del devenir del artista como figura literaria en las diversas tradiciones de habla hispana, en la multiplicidad de sus estrategias retóricas.

Palabras clave: artista, novela, Künstlerroman

\section{THE ARTIST HERO IN THE LATE $19^{\text {TH }}$ CENTURY NOVELLA}

\begin{abstract}
This paper addresses one of the most representative genres of the 19th century: the Künstlerroman (which developed at the same time the novel was imposing itself as the most prominent literary genre). The article provides an overview of the main narrative forms the Künstlerroman used, which are often differentiated based on their extension. Despite its German origins, the generic form also known as "artist's novel" flourished as well in the most important European literatures. Because of this, influential iterations of the genre were produced in the Hispanic tradition, which by the end of the century was a complex and rich context. In the article, a comparison between a long realist novel (El doctor Centeno by Benito Pérez Galdós), a much shorter postromantic novel (Confesiones de un pianista by Justo Sierra), and a modernist short story ("El pájaro azul” by Rubén Darío) is made in order to propose a compendious explanation of the artist as a literary figure in the different literatures that form the Hispanic tradition, in the variety of its rhetoric strategies.
\end{abstract}

Keywords: artist, novel, Künstlerroman

DOI: https://doi.org/10.24029/lejana.2020.13.436

Recibido: el 2 de noviembre de 2018

Aceptado: el 1 de marzo de 2019

Publicado: el 19 de febrero de 2020 
En su famoso poema "Enivrez-vous", Charles Baudelaire formula la siguiente triada: vino, poesía, virtud. Según este poeta, el hombre deberá tomar tales elementos a fin de vulnerar el spleen; tal procedimiento, al seguir el mismo texto, es legitimado por la voz poética cuando esta interroga a diversas figuras — símbolos, mejor dicho-. El campo isotópico de tal enumeración repele abruptamente la inmovilidad, lo invariable. En general, para el artista del siglo XIX —desde los románticos tempranos hasta los estetas del fin de siècle—, lo fijo sería una de las divisas de la vida moderna y burguesa, a la cual se opone la voz poética del texto baudelairiano y que cierto género novelístico, el Bildungsroman, también había rechazado en alguna medida, aunque con mayor fuerza en su vertiente que narra la formación del artista, es decir, el Künstlerroman.

Aunque la novela de artista surja en el romanticismo alemán, cuando se esboza una cronología no es difícil percibir que el héroe artista, desde Los años de aprendizaje de Wilhelm Meister de Goethe (1796) hasta las obras finiseculares que aquí se abordan con mayor minucia, circula por todas las estéticas literarias del siglo y a menudo es el protagonista de auténticas obras maestras. El género tiene por característica primordial la posición del creador como protagonista. De este rasgo puede intuirse una amplia red de variantes, por ejemplo, puede hacerse distinción entre Künstlerroman y artist-novel, pues el primero, como rama del Bildungsroman, se ocupa propiamente de la experiencia formativa del artista, mientras la segunda narraría las andanzas de un artista ya formado. Otro aspecto que se pone en tela de juicio es si discursos narrativos de menor extensión que ostentan a un creador como héroe forman o no parte del género. Esto es de especial relieve en este artículo, ya que esbozamos una comparación entre una novela típicamente realista, de gran extensión ( $E l$ doctor Centeno [1883] de Benito Pérez Galdós), una novelita posromántica (Confesiones de un pianista [1872] de Justo Sierra) y un cuento plenamente modernista ("El pájaro azul" [1888] de Rubén Darío), todas ellas obras narrativas finiseculares.

Antes de discurrir sobre el intrincado punto de la extensión de los textos narrativos, cabe señalar el estrecho vínculo entre la figura que nos ocupa y el auge definitivo del discurso novelístico, todo ello merced a determinados fenómenos que tienen lugar durante el siglo XIX y se consolidan en sus postrimerías. El arte literario de este panorama estuvo plagado de poetas, piratas, mujeres fatales, pintores, bohemios, dandis, seductores y algunos otros personajes cuya impronta es el afán de distinción y rebeldía. Puede pensarse en obras capitales como Illusions perdues (1837-1843) de Honoré de Balzac, Le Rouge et le Noir (1830) de Stendhal, The Corsair (1814) de Lord Byron, Il piacere (1889) de Gabriele D'Annunzio y The Picture of Dorian Gray (1890) de Oscar Wilde. La constante en dichas obras es el protagonismo de figuras con una marcada oposición frente a la sociedad utilitarista de su tiempo. Empero, fue el artista quien cristalizó con más eficacia esta vocación por enfrentarse al orden burgués. La conciencia de un orden más elevado, la preconización del poder creador e imaginativo, su vida errante y disipada, así como su búsqueda perenne de la belleza, constituyeron el más alto contrapunto a la sociedad burguesa y sus maneras. Del mismo modo, debe recordarse el actual interés del género por la existencia privada. Es entonces cuando la apasionante y enigmática vida de los artistas se convierte en materia narrable de primer orden.

Paralelamente opera un cúmulo de transformaciones que redefinirán los cimientos de la novela e incluso sellan su suerte crítica durante el siglo siguiente. Además de una forma 
inédita de narrar, la novela entra en un proceso de legitimación, del cual es representativo el "Prefacio" que Honoré de Balzac da a su Comédie humaine, y que se consolida en los tiempos en que D. H. Lawrence fraguaba sus opiniones sobre el arte novelístico en "Why the Novel Matters" (publicado de manera póstuma en 1936). Poco a poco, la novela se convierte en "el arte principal entre aquellas practicadas en Occidente, el arte que representa la totalidad amplia de la vida" (Mazzoni, 2011: 14-15). ${ }^{1}$

Para referir estos procesos, Guido Mazzoni utiliza la fórmula de paradigma decimonónico; y aunque la diversidad del corpus novelístico del XIX sea admitida por el teórico, y también por quien escribe estas líneas, el marbete se muestra de bastante utilidad para aludir a las reformas que la estética realista promulgó, y que fueron asumidas tiempo más tarde como rasgos característicos de la novela clásica, de una u otra forma, por críticos y escritores como Giacomo Debenedetti, André Breton, Edmund Wilson o Alain Robbe-Grillet. Sobre ello, Mazzoni menciona que "como arquetipo y semejanza de familia, se observa unido a una elección temática (la seriedad de lo cotidiano, el realismo existencial)" (2011: 252253). ${ }^{2}$

De aquí interesa sobre todo esa seriedad en la narración del entorno cotidiano, pues vale recordar que anteriormente solo los personajes nobles, míticos y capaces de englobar colectividades eran dignos de un tratamiento serio; la vida de la gente común era retratada en registros bajos y sin poder desprenderse de un tono didascálico o de entretenimiento. No obstante, al amparo de la estética romántica, la importancia de la personalidad y de la individualidad se acentúa, de modo que las artes nobles dejan de ocuparse solo de esos notables personajes y llegan a servirse de los actores de la vida cotidiana y la existencia privada. En opinión de Franco Moretti:

En otros términos: el "sentido de la historia", en la novela de formación, no tiene como su referente el "futuro de la especie": debe de manifestarse dentro de los más angostos confines de una existencia individual, circunscrita, y relativamente común. Y de allí se sigue que la novela se postula no como crítica sino como cultura de la vida cotidiana. Lejos de descalificarla, organiza y "civiliza" esta forma de existencia, volviéndola cada vez siempre más viva e interesante o incluso, con Balzac, fascinante. (2015: 39)

Ese sentido cristaliza en lo que Mazzoni define como una dimensión histórico-dinámica introducida a la novela por autores como Walter Scott y Honoré de Balzac, la cual sustituye los espacios narrativos más o menos indeterminados, dictados por un afán de orden universal o alegórico. Por esa razón el que Calvo Serraller afirmaría:

Las novelas de Stendhal y Balzac son los primeros libros que tratan de nuestra propia vida, de nuestros propios problemas vitales, de dificultades y de conflictos morales desconocidos para generaciones anteriores. Julien Sorel y Matilde de la Mole, Lucien de Rubempré y Rastignac son los primeros personajes modernos de la literatura occidental, nuestros primeros

\footnotetext{
1 "l'arte principale fra quelle praticate in Occidente, l'arte che raffigura la totalità estensiva della vita". Las traducciones del italiano son mías.

2 "in quanto idealtipo e somiglianza di famiglia, è tenuto insieme da una scelta tematica (la serietà del quotidiano, il realismo esistenziale".

3 "In altri termini: il "senso della storia", nel romanzo di formazione, non ha come suo punto di riferimento il 'futuro della specie': deve manifestarsi entro i piú angusti confini di un'esistenza individuale, circoscritta, e relativamente comune. E ne consegue che il romanzo si propone, non come critica, ma come cultura della vita quotidiana. Lungi dallo svalutarla, esso organizza e 'civilizza' questa forma di esistenza: rendendola via via sempre piú viva e interessante —o addirittura, con Balzac, affascinante”.
} 
contemporáneos intelectuales. En ellos encontramos por primera vez la misma sensibilidad que vibra en nuestros propios nervios, y, en la imagen de su carácter, los iniciales rasgos de la diferenciación psicológica que, a nuestro juicio, forma parte de la naturaleza del hombre actual. (2013: 29)

En el caso del artista, se torna posible el percibir su circunstancia de paulatina distancia y marginación por los senderos de la bohemia, el dandismo, los paraísos artificiales y demás, gracias al observatorio privilegiado en que el realismo introduce con su descripción microscópica, su milieu y con las típicas interjecciones del narrador a lo Balzac que advierte que fuera de París, o sin conocer este o aquel de sus recovecos, resulta imposible comprender el relato. Con este tipo de héroes y construcciones novelescas en verdad el lector hallaría figuras contemporáneas que no solo darían cuenta de su sociedad, sino que arrastrarían a un grado máximo de identificación comparable al del célebre y trágico Werther; un fenómeno que encuentra su raíz literaria en El Quijote, donde se inaugura la instancia temática del afán prometeico por llevar el mundo de los libros a la realidad. Dicha circunstancia será crucial en numerosas novelas de artista. No debe olvidarse, empero, la línea que preconiza una mímesis interior de dicho héroe y desestima un tanto la importancia del contexto histórico y social que este habita. Ambas vertientes, sin excluir su mixtura, aparecerán aquí al curso de la comparación que se postula entre las tres obras narrativas.

Ahora compete reparar en el marco de la novela y la novela breve. A decir de Óscar Mata: "Una novela corta es una pieza narrativa más grande que un cuento y no tan extensa como una novela o, si se quiere, más breve que una novela y menos pequeña que un cuento. Se trata de un género fronterizo cuyos límites ciertamente no están bien delimitados" (1999: 15). Sobre la imposibilidad de delimitación precisa, vale, por ejemplo, pensar en la prestigiosa colección que Italo Calvino dirigía para la editorial Einaudi, Centopagine. Al hablar de las pretensiones de esta, el italiano asienta que cada volumen "contendrá una novela completa que podrá tener unas ciento cincuenta o doscientas páginas, o quizá sólo noventa; más que en su dimensión, el criterio de selección se basará en la intensidad de una lectura sustanciosa que pueda encontrar un hueco incluso en los días menos tranquilos de nuestra vida cotidiana" (2006: 67). Calvino se refiere a un género de no menor importancia y de la misma valía que la gran novela clásica del siglo XIX, es decir, la novela breve o relato largo.

Por último, sobre este punto, se muestra clarificadora la opinión del mismo Mazzoni en la citada Teoria del romanzo:

Es raro que las librerías contemporáneas tengan una repisa específica dedicada a algo llamado "novela", mientras con frecuencia ocurre encontrar una sección dedicada al género que en francés y en inglés se llama fiction, y en italiano narrativa. En las casas editoriales se repite la misma división: las novelas, las autobiografías escritas con fines artísticos, los relatos son puestos en la misma colección, casi como si fuesen un subtipo de una especie más grande. Esto significa que nuestra cultura concibe todo texto narrativo escrito con pretensiones estéticas como parte de una única familia dentro de la cual las diferencias pesan menos que las semejanzas. (2011: 29-30) ${ }^{4}$

\footnotetext{
4 "È raro che le librerie contemporanee abbiano uno scaffale specifico dedicato a una cosa chiamata 'romanzo', mentre capita spesso di incontrare una sezione dedicata al genere che in francese e in inglese si chiama fiction, e in italiano narrativa. Nelle case editrici si ripete la stessa partizione: i romanzi, le autobiografie scritte per scopi artistici, i racconti vengono inseriti nella medesima collana, quasi fossero sottospecie di una specie più ampia.
} 
Con este cuadro en mente creemos que, en diversos aspectos, no conviene ver la novela del siglo XIX a través de los compartimientos de su mayor o menor extensión, sino bajo la premisa de su naturaleza proteiforme, pues, justamente por ello, fue preconizada y legitimada como ese arte principal de occidente en el cual fue, finalmente, posible hablar de cualquier vida real o posible y mediante cualquier estilo y extensión.

Aunque de cepa realista en más de un sentido, que se advierte ya desde su amplio número de páginas, El doctor Centeno es una novela de artista que no está exenta de numerosos elementos románticos. La multiplicidad de registros que presenta quizá deba mucho a la curiosa copresencia de dos protagonistas: el niño Felipe Centeno y el dramaturgo Alejandro Miquis. Además del cariño fraternal que se fragua entre ambos personajes, Galdós los hermana mediante una fuerte impronta cervantina que se manifiesta en la preponderancia de lo imaginativo. Miquis es retratado como un hombre de inclinada tendencia al fantaseo y ensimismado por sus pretensiones artísticas. Es un persecutor del ideal y un creador cuya obra se entremezcla con su vida:

¡Pobre Miquis, trabajador incansable de lo ideal, siempre imaginando, siempre creando! [...] ¡Desgraciado Miquis, siempre devorado del afán del arte; perseguidor con fiebre y congoja de la forma fugaz y rara vez aprehensible; atormentado por feroces apetitos mentales; ávido del goce estético, de esa inmaterial cópula con la cual verdad y belleza se reproducen y hacen familias, generaciones, razas! (Pérez Galdós, 322)

Una cuestión que ya abordó Charles Baudelaire en Les Paradis artificiels (1860) es que el hombre que intenta viajar a los terrenos de lo ideal (en este caso a través de los mecanismos potenciadores de la conciencia no ordinaria) comete una suerte de infracción y, por ello, está condenado a pagar altos costes. Por su tendencia a lo ideal, Miquis será confinado, como su amigo y protegido Centeno, "con los restos de todo lo útil, algo que es como desperdicio vivo, lo que sobra, lo que está de más, lo que no tiene otra aplicación que descomponerse moralmente y volver a la barbarie y al vicio" (Pérez Galdós, 243).

En forma complementaria, la figura de Felipe Centeno es la de un niño llegado a Madrid, proveniente de un pueblo minero y ficticio llamado Socartes, que ha viajado hasta allí con la firme intención de destruirse, como dice a su futuro amigo y compañero de bohemia, Alejandro Miquis. Lo que ha querido referir el niño es su voluntad de obtener instrucción, pero Galdós lo ha dotado, como a diversos personajes de su monumental obra, con una fijación por alterar ciertas palabras. En este caso, el personaje concibe este mecanismo como una forma de distinción que lo asemeja a un gentilhombre.

Por lo demás, en esta novela, mediante la narración de las pretensiones artísticas de Miquis y la desventurada bohemia que vive junto a Felipe, el escritor canario traza un fresco melancólico y, a la par, satírico de la visión romántica de la vida. No obstante, el binomio de héroes es excelente ejemplo del personaje romántico. Con respecto al niño, es ilustrativo recordar el pasaje donde toma una cabeza de toro, que formaba parte de una escultura de San Lucas, y lleva al límite la verosimilitud de su ejercicio lúdico. Aunque el personaje reflexiona sobre las posibles consecuencias de su actuar, es dominado por el impulso de aventura y de fantasía:

Questo significa che la nostra cultura concepisce ogni testo narrativo scritto con intenti estetici come parte di un'unica famiglia all'interno della quale le differenze pesano meno delle somiglianze". 
El alma de Felipe despedía centelleos de esperanza, de temor, de miedo, de alegría. Andaba por la casa afanadísimo, desplegando una actividad febril para desempeñar en poco tiempo todos los servicios que le correspondían aquella tarde.

Había formado propósito de escaparse si no le dejaban salir. Estaba frenético. Su anhelo era más fuerte que su conciencia. (Pérez Galdós, 128)

Dicho ejercicio funciona como preámbulo de su andanza bohemia que ha de convertirse propiamente en fantaseo, en forma similar a como Freud utiliza el término en su ya célebre artículo "El creador literario y el fantaseo". 5

Aunque presente en novelas decadentistas como Il piacere de D’Annunzio, o incluso ya desde La Peau de chagrin (1831) de Balzac, la inclinación al fantaseo no tendrá el mismo peso en la confección del héroe creador por parte de Justo Sierra en su novelita.

La novela de artista, en el marco de la literatura mexicana finisecular, no estaba exenta de particularidades y variaciones, las cuales iban de la mano de una convergencia de corrientes estéticas que traslapaba realismo, modernismo, decadentismo y posromanticismo. Para precisar este panorama, recordamos cierta polémica que incluyó a uno de los novelistas más conspicuos de la época, Victoriano Salado Álvarez, quien, en esos años, se permitía un proyecto novelístico de gran calado, a la manera de la Comedia de Balzac o los casi homónimos Episodios nacionales del propio Galdós. Para confeccionar su ciclo de novelas, Episodios nacionales mexicanos (1902-1906), el autor acudía también a la poética realista, la cual no solo se vinculaba con su faceta como historiador, asimismo correspondía con la concepción de una patria literaria que, para Salado, poco tendría que ver con el afrancesamiento y decadencia, más que decadentismo, que percibía en los autores modernistas. Este contrapunto desató una polémica cuyo campo de batalla fue la prensa, principalmente, y suscitó los embates de Amado Nervo y José Juan Tablada. Al paralelo de todo ello, otra tormenta romántica aún acontecía, $\mathrm{y}$, al amparo de esta, ciertos temas y motivos reaparecen en escena, de modo que ciertas estructuras narrativas se reactivan. De allí que las andanzas del héroe artista sean narradas, como en el caso de Confesiones de un pianista, con estrategias sumamente cercanas al Künstlerroman de los primeros románticos, en gran similitud a como ocurrió con la recepción del género en el ámbito de la scapigliatura italiana, con Iginio Ugo Tarchetti a la cabeza y sus novelas breves sobre músicos que agrupó bajo del título de Amore nell'arte (1869).

Es esa la trayectoria que sigue Sierra en el desarrollo de su obra, pues justamente establece un sugerente nexo, de cuño romántico, desde luego, que engarza amor y arte, pero también muerte, como, por lo demás, es también tangible en los relatos del scapigliato. María Eugenia Negrín, en su estudio que forma parte de una reciente antología de Sierra para el Fondo de Cultura Económica, advierte también esa línea que conjuga amor y fatalidad, dicotomía a la que es necesario añadir el impulso creativo. Esto es perceptible desde el inicio de la narración, cuando Antonio está frente al lecho de muerte de un querido amigo, y mezcla sin reparo su perspectiva estética y la pulsión de muerte:

Yo estaba conmovido. Una extraña sobreexcitación dominaba en mi sistema nervioso. El murmullo de las preces que recitaban junto al lecho del enfermo, Luisa, mi tía y otras personas arrodilladas, y el eco sordo de la respiración calenturienta de Eduardo; el perfume de las flores

\footnotetext{
5 "Der Dichter und das Phantasieren", famosa conferencia que Freud da en 1907 y que, en 1908, se publicó como artículo.
} 
y el olor peculiar de la habitación de un tísico, todo eso hería mis sentidos y provocaba en mí sensaciones que no podía analizar.

Cuando se presentó en la puerta el sacerdote con su pequeña capa blanca, recamada de flores de oro, rodeado de luces y de personas prosternadas, sentí yo no sé qué impresión para mí desconocida. El brillante marfil del piano me fascinaba, me parecía una faja luminosa en la que se movían siluetas fantásticas, creaciones sin duda de mi cerebro exaltado. Mi boca estaba seca y mis manos heladas. (Sierra, 2018: 22)

Ante el lecho de su amigo Eduardo, Antonio, el pianista, halla un espacio en que su percepción de artista se exalta; los sentimientos, que la cercanía de la muerte gesta, avivan el fuego de la creación. En los ritos cristianos, el personaje encuentra un auténtico nexo con lo divino, de allí que el fenómeno sea homologado con el ritual creativo, sobre todo aquel romántico, que establece una dialéctica entre ámbito terrestre y ámbito divino.

En absoluto lejana es la perspectiva que Rubén Darío ofrece en "El pájaro azul”, basta con acudir al íncipit: "París es teatro divertido y terrible. Entre los concurrentes al Café Plombier, buenos y decididos muchachos — pintores, escultores, escritores, poetas; sí, ¡todos buscando el viejo laurel verde!-, ninguno más querido que aquel pobre Garcín, triste casi siempre, buen bebedor de ajenjo, soñador que nunca se emborrachaba $\mathrm{y}$, como bohemio intachable, bravo improvisador" (Darío, 83).

Si Galdós concede unas páginas para retratar a Centeno e, implícitamente, fijar un programa narrativo al comienzo de su novela, Darío, quien se mueve en el relato de más breve extensión de los aquí abordados, de golpe ofrece un conjunto de rasgos característicos del héroe artista. Se califica a Garcín "de vino triste", aludiendo al topos tan recurrente y significativo en el ídolo poético de Darío: el saturnal Verlaine, a quien se debe, por cierto, gran parte de la configuración literaria del héroe artista finisecular, sobre todo en su vertiente bohemia y maudit.

Entre los artistas, la institución de los cenáculos fue una práctica común, que estaba en consonancia con el espíritu romántico de la interrelación de las artes impulsado por las ideas estéticas de Richard Wagner acerca de una obra de arte total; por la tendencia del método narrativo realista hacia las artes de la esfera pública (pintura y teatro) y en sincronía con la aspiración a lo musical que ostentaba la poesía, visible claramente en programas como el de Paul Verlaine o el de Gabriele D'Annunzio. Es así que practicantes de artes varias conviven - justo como en el cuento dariano - e intercambian puntos de vista y, en muchas ocasiones, acuñan una estética común a pesar de utilizar métodos discursivos disímiles.

Por lo demás, el escenario del café durante el siglo XIX se convierte en lugar de convivencia característico de la ciudad — particularmente para los artistas - y punto de fuga para que el personaje deguste una especial sensación frente a la multiplicidad de existencias que es solo posible - y casi su rasgo distintivo - en el nuevo ritmo de vida que se experimenta en las grandes urbes, y del que el creador extraerá una expresión también nueva, un trazo moderno.

No es azaroso el que en esta época se consolide el mito literario de París, que queda patente en el cuento de Darío, con una influencia que persiste hasta las vanguardias del siglo xx. Al pensar en el género que nos ocupa, la novela de artista, no queda sino admitir que es la ciudad su escenario por excelencia. Coincidimos con Franco Moretti: "No hay una picaresca de la frontera, ni un Bildungsroman del europeo en África: para que se dé esa forma 
específica es necesario ese espacio específico; el camino, la gran ciudad (Moretti, 74). Así, difícilmente hay Künstlerroman en un sitio distinto de las grandes urbes, como también se atisba en las andanzas del dramaturgo Alejandro Miquis.

No obstante las diferencias, vale reparar por última vez en el cierre del cuento dariano, que concluye justamente con un verso escrito por su protagonista, como paralelo al final de $E l$ doctor Centeno con la reflexión sobre el arte literario, entre Felipe Centeno y José Ido del Sagrario, escrita a modo de diálogo teatral. A fin de cuentas, mundos gestados por la literatura y el arte que no pueden mantenerse en pie sin la reflexión estética y la creación; cuyo trazo final debe ser pluma de pájaro azul.

En las tres obras resalta esa mitificación del héroe artista tan propia del siglo XIX que inició con el célebre Tasso de Goethe, el prestigio de Lord Byron o la figura de Lucien de Rubempré tan admirada por Oscar Wilde. Un esplendor que fue paralelo al ascenso del discurso novelístico, el cual llegó a convertirse en forma hegemónica del arte literario. Vale considerar allí tanto los proyectos monumentales como las formas breves.

\section{Bibliografía}

CALVINO, Italo (2006): Mundo escrito y mundo no escrito. Madrid, Siruela.

CALVO SERRALLER, Francisco (1990): La novela del artista. Madrid, Fondo de Cultura Económica.

DARÍO, Rubén (1905): Azul. Buenos Aires, Biblioteca de La Nación.

MATA, Óscar (1999): La novela corta mexicana en el siglo XIX. México, Universidad Nacional Autónoma de México.

MAZZONI, Guido (2011): Teoria del romanzo. Bolonia, Il Mulino.

MORETTI, Franco (1999): Atlas de la novela europea 1800-1900. Traducción de Stella Mastrangello. México, Siglo XXI.

MORETTI, Franco (2015): Il romanzo di formazione. Turín, Einaudi.

PÉREZ GALDÓS, Benito (1975): El doctor Centeno. Madrid, Aguilar.

SIERRA, Justo (2018): Confesiones de un pianista. Presentación de Christian Sperling. Edición y notas de Karla Ximena Salinas Gallegos. La novela corta. Una biblioteca virtual. Colección Novelas en Tránsito - Segunda Serie. Dir. Gustavo Jiménez Aguirre. Recuperado de http://www.lanovelacorta.com/1872-1922/cup00.php, [05-092018]. http://lanovelacorta.com/novelas-en-transito-2/confesiones-de-un-pianista.pdf

(C) Diego Mejía Estévez

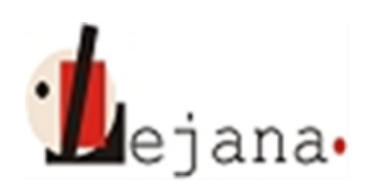

http://ojs.elte.hu/index.php/lejana

Universidad Eötvös Loránd, Departamento de Español, 1088 Budapest, Múzeum krt. 4/C 